\title{
The practice of bilingual teaching of College Physics
}

\author{
Chen Lei \\ School of mathematics and Physics \\ North China Electric Power University \\ Beijing P.R. China \\ E-mail: chlei@ncepu.edu.cn
}

Keywords: Bilingual teaching; College physics

\begin{abstract}
The aim of bilingual teaching is to improve the students' ability of reading the English-writing textbooks and enlarge the field of view of the newest progress of science in the world. The bilingual teaching of College Physics improved the students' abilities of understanding of English and the knowledge of physics.
\end{abstract}

\section{Introduction}

In China, there are more and more universities practicing bilingual teaching. Bilingual education means that the teachers use two different languages to teach in the class. One language is the mother tongue--Chinese, and the another language is foreign language. Nowadays, the second language is English mostly. The aim of bilingual teaching is to improve the students' ability of reading the English-writing textbooks and enlarge the field of view of the newest progress of science in the world. The students are those who want to keep on studying in the English-speaking counties. So the students want to improve the ability of understanding of English and the ability of understanding of the knowledge of disciplines.

In NCEPU, there are more than 100 students who will go to U.S.A. England and other countries to continue study in the field of the Electric power and Energy every year. These students have studied English for many years, and can read the basis English book or maybe have passed the examination like TOEFL and so on. They also have studied mathematics for one semester using English textbook. But they cannot read the professional books fluently. The College Physics begins in the second semester. All of them have studied physics in the middle school, so they can understand the basis concepts of physics in Chinese. So the difficulties which we faced are how to improve the students' ability to understand the basis concept of physics and how to teach them to learn think in English. In our practices, we have made the progress in the following:

1. The students can read the textbooks of physics quickly and understand the basis concepts correctly after studying physics one year.

2. The most of students can answer the questions in English in the class, and can do homework in English. They also can take the examination in English.

3. Each student can write a paper about the newest progress of science which the topic is interested by him when ending the course of physics.

The students of the first class had entered the department of Electric Power Engineering of the University of Strathclyde, UK in 2006. In the summer of 2008, they have got the degree of bachelor. Most of them continued to study in England as graduate. Some of them have entered to the University of Cambridge and other top universities. For these years, more than 1000 students have studied in abroad, and most of them have finished their university education. We have got some information from the overseas universities that the students have solid linguist foundation and mathematic and physics foundation. 


\section{The basis methods of teaching}

To select a avialable textbook. The textbook is very important for the students. First the text must be written by the nature English-speaker. Then the text must be understood easily. Third the text must be interested by the students. We choose <Principles of Physics----A Calculus-Based Text> (third edition) by Serway \& Jewett. In this text the concept is introduced clearly. And the language is not difficult to understand. The examples are typically. And the questions and problems are not boring which many questions selected from the real-life. And in this textbook, there are many interpretation about famous physicist's life story and their scientific contributions. We also introduce to students some references: $<$ Physics for Scientists and Engineers with Modern Physics> (Third Edition) by Douglas C. Giancoli; $<$ Fundamentals of Physics> (Sixth Edition) by David Halliday, Robert Resnick, Jearl Walker, published by John Wiley \& Sons.

To translate the professional words and phrases for the students. In the each chapter, we first explain some professional words and phrases for the students. The following is a example:

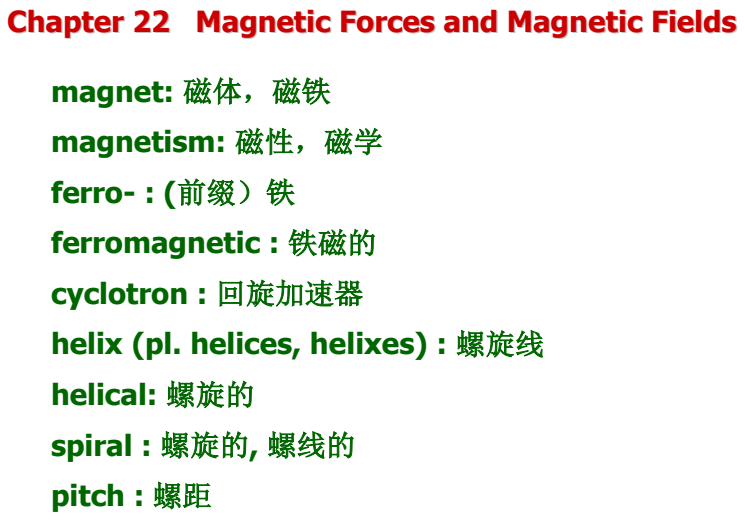

It is helpful for the students to understand the text. And the students can quickly to read the text.

To select some articles about the scientists' biography. In order to enhance students' interesting in the studying, we select many articles about the scientists' biography, such as Newton, Maxwell, Faraday Einstein and so on. The students can improve their interesting and can understand the physics concepts more easily. For example:

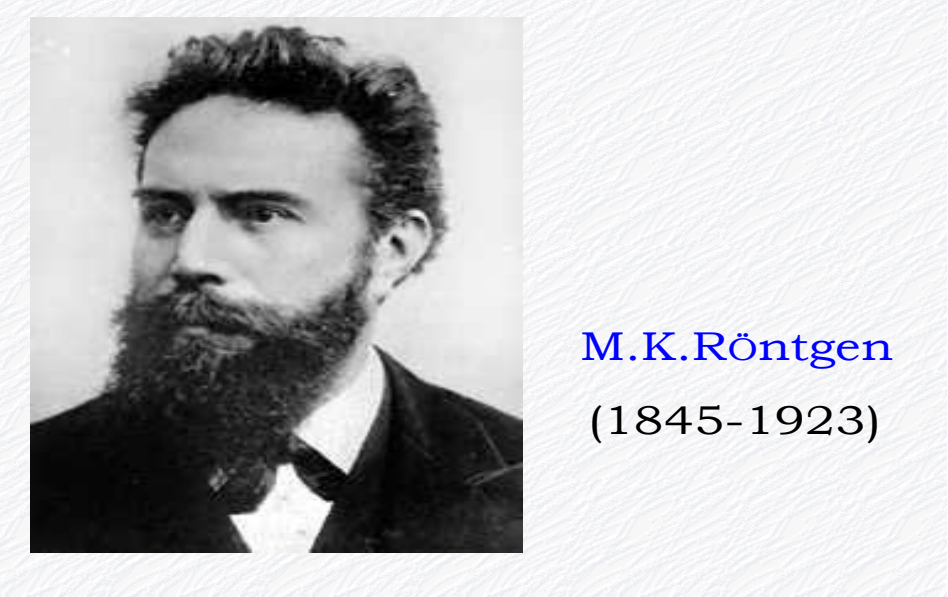

To prepare the animation Many physics law can be expresses in animation. It is very helpful for the students to understand the physics phenomenon. For example: 


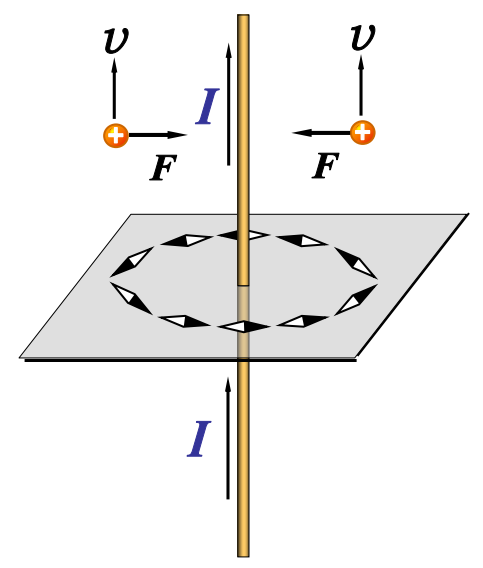

\section{Computers in physics teaching}

Using computers as calculating machines has been known long ago. This is a natural transfer from research experience into the teaching arena. Another instance of this kind is using computers in the laboratory for experimental data processing. As soon as relatively inexpensive desktop computers became available, we started using computers in laboratories for students to process data.

Now, computers are being used widely for computer-assisted learning purposes. We have used the computer's excellent graphics capabilities, and to create animated graphics. We used this animated graphics to teach the physics concept and explain the Phenomenon more easily. Although computers have obvious limitations when compared to human tutors, they also have certain advantages over human tutors. Students appreciate being able to take their time when working with computers and prefer the anonymity and independence provided by this form of tutoring.

\section{Practicing in the class}

In the each lecture, we should prepare the materials carefully. We divided the material from each course into core material and optional suggested material. We agreed that the core material of a course should always be taught, either because the core was deemed to be an essential part of our students' education or because it was part of the expected background for a subsequent course. The optional material was intended to allow individual instructors to structure a course according to their preferences.

In our class, five to ten minutes of every class were set aside for answering one or two questions projected on an overhead. The students were asked to work in groups of three or four for this purpose. The composition of the groups remained the same for a month; the following month entirely new groups were formed. The questions were related to the same lecture, and students had to hand in their answers for marking. The marked answers were returned at the beginning of the next class, and students received bonus points for their work in this exercise. This worked well on the whole. Students can answer the questions correctly gradually. And the students like this form in the class.

\section{Conclusion}

In our practicing, we can get the conclusions as following: 
1. Nowadays, in China the bilingual teaching is very helpful for the students. Not only for the students who want to study in abroad, but also for the students who want to continue to study as a graduate student.

2. The students have the abilities to study professional knowledge in English. Just need the teachers use a appropriate method to teach.

There are many practices want us to make, and many experience wait us to conclude.

\section{Acknowledgment}

This work was supported by "The teaching reform project of Beijing” (2014-ms114).

\section{References}

[1] Raymond A. Serway \& John W. Jewett Jr., Principles of Physics----A Calculus-Based Text, (Fourth edition) Thomson Brooks/Cole 2012.

[2] Douglas C. Giancoli, Physics for Scientists and Engineers with Modern Physics, (Third Edition); Higher Education Press, 2005

[3] David Halliday, Robert Resnick, Jearl Walker, Fundamentals of Physics, (Sixth Edition) John Wiley \& Sons, 2013.

[4] Ma Wenwei, Physics (part 1) (Fifth Edition) Higher education Press 2009.

[5] Ma Wenwei, Physics (part 2) (Fifth Edition) Higher education Press 2009.

[6] Andersson I \& Rusanganwa J. Language and space in a multilingual undergraduate physics classroom in Rwanda [J]. International Journal of Bilingual Education and Bilingualism, 2011, $14(6): 751-764$.

[7] ZHENG Dahu \& DAI Weihua, bilingual teaching in China for ten years. Foreign Language World, 154 (2013.1) 54-61.(in Chinese) 